\title{
SoluÇÃo Alternativa NA Gestão de Resíduos Sólidos EM INDÚSTRIA METALÚRgICA
}

\author{
Sidarta Ruthes \\ Mestrando em Tecnologia pela PPGTE, Professor de \\ Empreendedorismo e Plano de Negócios - HCI. \\ sidarta@ppgte.cefetpr.br \\ Prof. Paulo Sérgio Ceretta \\ Prof. Adjunto do Departamento de Administração da \\ UFSM, Doutor em Engenharia de Produção pela UFSC. \\ ceretta@smail.ufsm.br \\ Michael Ruthes \\ Graduando em Engenharia \\ de Produção Civil pela UTFPR. \\ michaelruthes@gmail.com
}

\section{RESUMO}

É cada vez mais indiscutível a importância dos aspectos ambientais a nível empresarial, apesar de muitas vezes esta importância ser uma conseqüência da obrigatoriedade com que muitas empresas estão comprometidas. Em muitos casos, as organizações são obrigadas a se submeterem às responsabilidades com o governo e entidades reguladoras, bem como a pressões de organizações não-governamentais e ao próprio cliente, tudo para preservar ou construir uma imagem num mercado altamente competitivo. Dentro desse contexto, este artigo tem como objetivo relatar um exemplo prático de redução do impacto ambiental através da aplicação dos próprios resíduos metálicos na construção de caçambas para a coleta de materiais recicláveis. Foi utilizado como método de pesquisa o estudo de caso exploratório, através de dados primários coletados junto à Empresa $\mathrm{X}$, e dados secundários extraídos da internet, pesquisa bibliográfica e pesquisa documental. Neste estudo ficou claro que a organização conseguiu alguns benefícios operacionais, como organizar melhor sua instalação fabril, limpeza e redução de tempo com o trabalho de coleta e armazenamento de material reciclável. Por fim, é importante ressaltar que a empresa conseguiu vender o resíduo reciclável por preços mais altos, devido à oferta de uma maior quantidade de material e à redução do desperdício causado pela armazenagem incorreta desses materiais que, anteriormente, ficavam se decompondo nas dependências da organização.

Palavras-chave: Custo Ambiental, Gestão Ambiental, Armazenagem de Resíduos.

\section{ABSTRACT}

It's unquestionable the importance of the environmental aspects in the enterprise scope, although, that many times this importance to be a consequence of the obligatoriness that many companies are compromised. In many cases, the organizations are obliged to submit the certain responsibilities with the government and regulating entities, as well as pressures of not-government organizations and the proper customer, everything to preserve or to construct an image in a competitive bighly market. In this context, this article has as objective to tell about a practical reduction's examples of the environmental impact through the application of the proper metallic residues in the construction of dumps-cart. It was use as research method the exploration case study, through primary data collected of the Company $X$, and secondary data extracted of the internet, bibliographical research and documentary research. In this study, it was clearly that the organization obtained some operational benefits, as to better organize its installation manufacture, cleanness and reduction of time with the collection work and storage of recycling material. Finally, it's important to stand out that the company obtained to send the recycling residue for higher prices, due to offers of a bigger amount of material and the reduction of the wastefulness caused for the incorrect storage of these materials that, previously, were decomposing itself in the dependences of the organization.

Key words: Environmental Cost, Environmental Management, Storage of Residues. 


\section{INTRODUÇÃO}

Em muitas empresas, o sistema de gestão ambiental já é reconhecido como uma função organizacional independente e necessária, que possui características próprias que a distinguem das outras funções das organizações. Com a disseminação dos conceitos de garantia de qualidade total, a gestão ambiental passou a ocupar uma posição de destaque entre as funções organizacionais, não somente pela contribuição positiva que agrega à imagem de qualidade da empresa, como também pelos efeitos danosos que um mau desempenho ambiental pode causar a essa imagem, sem mencionar os aspectos de custos inerentes a uma gestão ambiental inadequada.

Hoje em dia, é possível encontrar empresas de maior porte que dispõem de departamentos voltados para o tema ambiental e que tratam de questões como: uso racional de matérias-primas, insumos, energia, água e ar, como também se preocupam com processos produtivos que causem menores danos à natureza, mediante a redução de lixo, despejos e degradação ambiental em geral.

Além disso, algumas pesquisas e fatos apontam para a existência de barreiras de importação para produtos provenientes de países que não desenvolvem programas de incentivo à proteção do meio ambiente. Esse fato revela a importância de aliar as estratégias empresariais com projetos sustentáveis. Um estudo realizado por Pieniz (2001) evidenciou que alguns países criaram políticas protecionistas em nome do "desenvolvimento sustentável”, ou seja, barreiras de importação para produtos provenientes de países que não desenvolvem programas de incentivo à proteção do meio ambiente.

Esses pontos, por si só, evidenciam a importância que os sistemas de gestão ambiental vêm alcançando em várias empresas para atenderem objetivos específicos internos e/ ou exigências externas. O presente artigo visa explicitar uma ação de redução do impacto ambiental através da aplicação dos próprios resíduos metálicos na construção de caçambas e contêineres para coleta de materiais recicláveis. Esta pesquisa aborda três objetivos mais específicos: (i) investigar quais as principais vantagens e desvantagens, em termos operacionais e econômicos, com relação à confecção de caçambas e contêineres a partir de materiais recicláveis; (ii) evidenciar os principais benefícios quanto aos aspectos ambientais; e, (iii) evidenciar o seu caráter inovador.

Inicialmente, apresenta-se uma revisão de literatura, com referências de publicações a respeito da questão ambiental, custos e temas correlatos. Após, encontra-se explicitado o método aplicado neste estudo, com a caracterização do trabalho e da empresa pesquisada. Na seqüência, os dados empíricos relativos aos benefícios alcançados pela organização e, por fim, as considerações finais da pesquisa.

\section{GESTÃO AMBIENTAL: ASPECTOS GERAIS}

Um dos grandes desafios para a gestão ambiental é criar sociedades sustentáveis, pelo menos essa é uma das afirmações de Born (2000). A sustentabilidade só é possível através de esforços como educação fundamental, mudanças nos sistemas de transporte e no desenho institucional de organizações, alteração nos padrões de consumo e produção, incentivo à inovação tecnológica sustentável, e, principalmente, participação e mobilização de indivíduos e grupos da sociedade nas decisões e ações pertinentes ao meio ambiente.

Braga et al. (2002) afirmam que o modelo de desenvolvimento utilizado pela sociedade, até atingir seu atual estágio, é representado por um sistema aberto. Este sistema aberto depende de um suprimento contínuo e inesgotável de matéria e energia que, depois de utilizada, é devolvida ao meio ambiente.

Se considerarmos verdadeira a premissa de que o Sol é uma fonte inesgotável de energia, podendo fornecer energia à Terra por 5 bilhões de anos, o mesmo não se pode afirmar quanto à matéria (recursos naturais), já que sua quantidade é finita. Dentro desta realidade, o meio ambiente possui limites quanto à capacidade de absorver e reciclar matérias e resíduos, tendo a humanidade problemas como níveis indesejáveis de poluição. Portanto, o próximo estágio é reformular este modelo de desenvolvimento baseado em um sistema aberto, através do conhecimento e de técnicas científicas que, em prol da humanidade, possam criar um sistema fechado e sustentável, conforme a Figura 1.

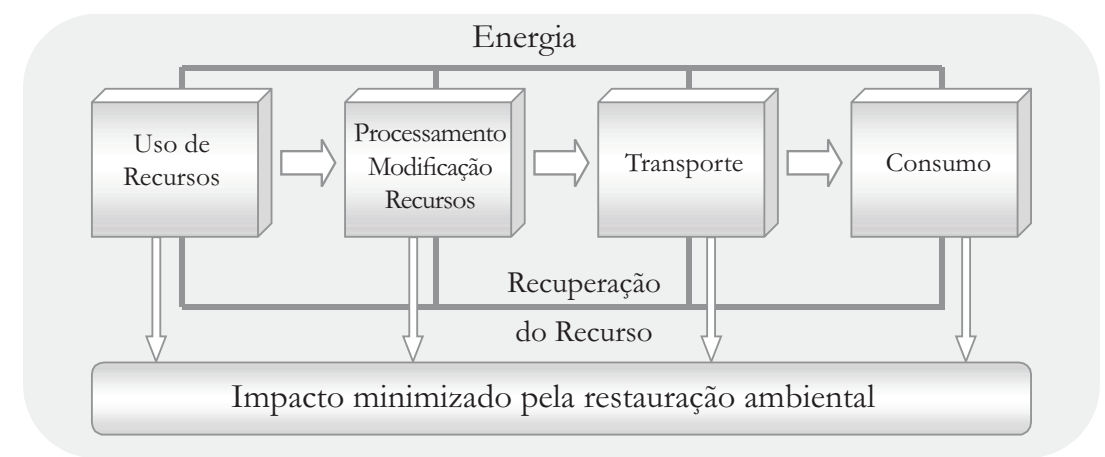

Figura 1: Modelo de desenvolvimento sustentável: sistema fechado Fonte: Adaptado de Braga et al. (2002, p. 48). 
ou são recuperados através de ações restauradoras que minimizem o impacto ambiental. Este modelo é caracterizado por ser um sistema fechado, onde não há saídas ou devolução de resíduos para o meio ambiente.

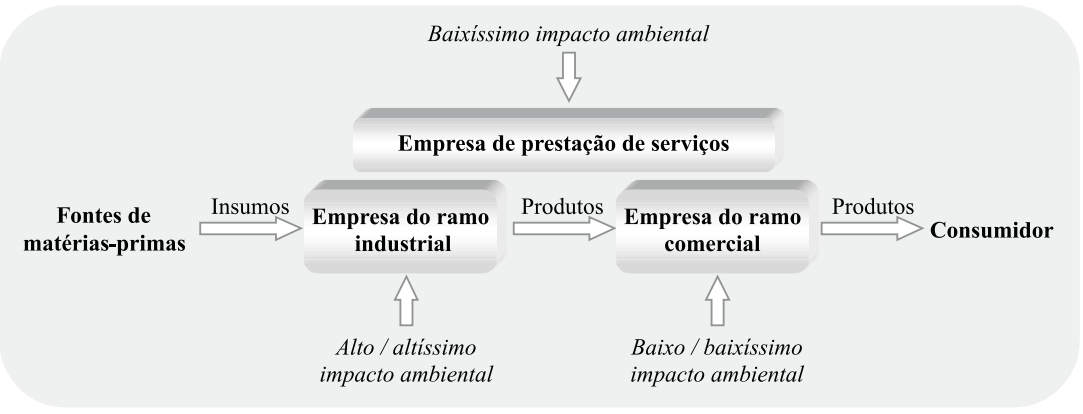

Figura 2: Setores econômicos e impactos ambientais

Fonte: Adaptado de Andrade, Tachizawa; Carvalho (2002, p. 45).

Dentro desse contexto, existem diversos tipos de impactos ambientais e ecológicos que as organizações causam no meio ambiente. Andrade et al. (2002) classificam as empresas e seus respectivos impactos ambientais e ecológicos. As organizações que mais geram impactos ambientais são do ramo industrial, dada por sua característica de serem transformadoras de insumos produtivos em produtos finais. Como as empresas do ramo comercial realizam a intermediação dos bens produzidos pelas companhias industriais, os impactos ambientais e ecológicos são de moderada intensidade. Já as empresas prestadoras de serviço são as que provocam o menor impacto ambiental, conforme a Figura 2. Nesse sentido, o consumidor final tem o papel de agente que induz às mudanças internas nas organizações. Isto é devido a uma maior conscientização dos efeitos ambientais que essas organizações e seus produtos causam no meio ambiente.

Além disso, a administração de recursos naturais é uma questão muito discutida atualmente na gestão ambiental. Braga et al. (2002) classificam os recursos naturais em dois grupos: (i) recursos renováveis (depois de serem utilizados ficam disponíveis novamente, devido aos ciclos naturais); e, (ii) recursos não-renováveis (uma vez utilizado, não pode ser aproveitado). O controle responsável dos recursos naturais é fundamental para a manutenção dos organismos, populações e ecossistemas. Dentro desse contexto, há uma interligação entre recursos naturais, tecnologia e economia. Essa interligação pode ser evidenciada com a necessidade de processos tecnológicos para utilização de um recurso, onde há um envolvimento entre recursos naturais e tecnologia. Já a interação entre os recursos naturais e a economia é bastante evidente, uma vez que algo é recurso na medida em que sua exploração é economicamente viável. Por fim, algo se torna recurso natural caso sua exploração, processamento e utilização não causarem danos ao meio ambiente.

Assumindo a premissa de que toda a tomada de decisão envolve algum risco, na gestão ambiental não é um caso a parte e existem vários estudos realizados sobre a temática do risco em relação à gestão ambiental. Lage (2003) destaca o passivo ambiental como fator de risco e o define como sendo alguma deficiência existente nas áreas de segurança, saúde e proteção ambiental, cuja solução pode significar investimentos, ou mesmo, pode impedir a continuidade do negócio em avaliação. Figueiredo (2001) salienta a importância da simulação como gerenciamento e tomada de decisão baseada no risco. A simulação é uma ferramenta gerencial para avaliar as alternativas de projetos, planos e políticas sem a necessidade de experimentações em um sistema real.

Segundo Andrade et al. (2002), as empresas do ramo industrial, mais especificamente as organizações metalúrgicas, devem estabelecer estratégias ambientais visando: (i) eliminação de questões legais com o governo através de estrita observância à legislação vigente; (ii) redução de dispêndios com insumos produtivos mediante racionalização por meio de seus métodos operacionais; (iii) criação e aprimoramento de seus processos produtivos, com a eliminação/redução de perdas e geração de resíduos ao longo da cadeia de agregação de valores; (iv) eliminação, criação e/ou aperfeiçoamento de produtos a serem ofertados ao mercado, dentro do contexto ambiental e ecológico; e, (v) redução ou eliminação de riscos ambientais. Andrade et al. (2002) destacam, ainda, a atitude de várias empresas que se uniram para formar associações de administração ambiental, cujo papel é fazer com que o maior número possível de empresas pratiquem a administração ambiental.

\section{CUSTOS DA QUALIDADE E CUSTOS AMBIENTAIS}

Dentro do contexto ambiental, existem abordagens gerenciais que visam à qualidade organizacional como um todo, como a gestão de custos ambientais e custos relacionados à qualidade. De acordo com Campos (1992), o Total Quality Control - TQC é um sistema administrativo que é baseado na participação de todos os empregados da empresa no que diz respeito ao estudo e condução do controle da qualidade. As principais dimensões de um TQC podem ser assim resumidas: (i) qualidade (produto/serviço e rotinas/ operações); (ii) custo (custos e preços detalhados); (iii) entrega (prazo, local e quantidade certa); (iv) moral (satisfação dos empregados); e, (v) segurança (empregados e clientes/ usuários dos produtos).

Antigamente, os especialistas e profissionais da área de produção acreditavam que obter produtos de melhor 
qualidade acarretaria, consequentemente, um aumento dos custos. Davis et al. (2001) relataram que Edwards Deming demonstrou ser menos custoso para as organizações um processo de alta qualidade, pois ele acreditava que os produtos deveriam ser feitos corretamente desde a primeira etapa. Com isso, economias substanciais poderiam ser obtidas a partir da eliminação de retrabalhos e refugo de materiais não-conformes.

Para Slack et al. (1997), o melhoramento da qualidade contribui para o aumento da lucratividade da empresa. Através da alta qualidade, as receitas podem ser incrementadas por melhores vendas e por preços mais elevados. Além disso, os custos podem ser reduzidos pela melhor eficiência, produtividade e uso do capital. As operações de alta qualidade não desperdiçam tempo ou esforço com retrabalhos, sucatas e materiais refugados. Slack et al. (1997) ressaltam, porém, que o custo do controle da qualidade pode não ser baixo sendo, portanto, necessário um exame de todos os custos e benefícios associados com a qualidade.

Os custos da qualidade existem porque a má qualidade existe. Segundo Feigenbaum (1994), Robles Jr (1994), Hansen e Mowen (2003), os custos da qualidade podem ser classificados de acordo com as seguintes categorias: (i) custos de controle; e, (ii) custos das falhas dos controles, conforme a Figura 3. Os custos de controle englobam os custos de prevenção (gastos para assegurar a qualidade desejada); e, custos de avaliação (gastos relacionados com as atividades de identificação dos produtos e serviços defeituosos). Já os custos relacionados às falhas dos controles podem ser classificados em custos das falhas internas (associados às atividades decorrentes de falhas internas) e custos das falhas externas (associados às falhas externas, após a entrega do produto ao cliente).

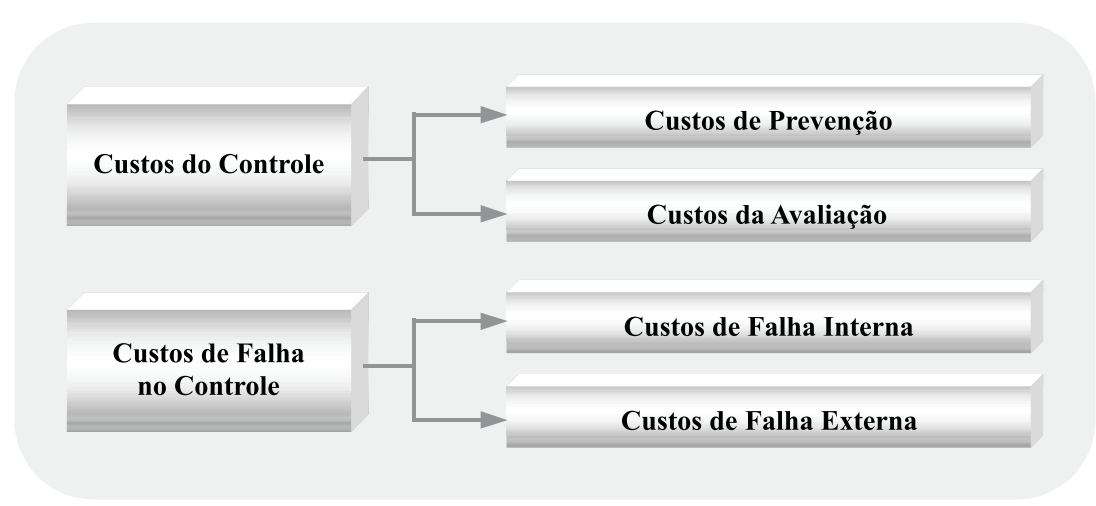

Figura 3: Classificação dos custos da qualidade

Fonte: Adaptado de Feignebaum. (1994, p. 152).

Hansen e Mowen (2003) afirmam ainda que, à medida que os custos de prevenção aumentam há uma diminuição dos custos de falhas. Programas de treinamento de qualidade, planejamento de qualidade, auditorias de qua- lidade são alguns exemplos de custos de prevenção. Em contrapartida, os custos de avaliação são incorridos para determinar se os produtos e serviços estão em conformidade com as especificações ou necessidades dos clientes, por exemplo, inspeções, supervisões das atividades de avaliação e aceitação do produto.

Os custos de falhas correspondem aos produtos nãoconformes e inoperantes. Davis et al. (2001) define os custos de falhas internas como gastos que podem ser eliminados quando não são produzidos defeitos no sistema produtivo. As falhas internas são detectadas até a entrega dos produtos aos clientes, por exemplo, retrabalho, refugo, disposição de itens defeituosos. Por outro lado, os custos de falhas externas são incorridos após o produto ter sido entregue ao consumidor, por exemplo, devolução de material, garantia, insatisfação do cliente. Para Ritzman e Krajewski (2003), os custos de falhas internas podem ser classificados, ainda, em duas categorias principais: (i) perdas de lucro (quando um item defeituoso precisa ser refugado); e, (ii) custos de retrabalho (quando um item é encaminhado novamente a alguma operação prévia para correção do defeito).

Existe também outra classificação dos custos da qualidade. Hansen e Mowen (2003) enfatizam que a dificuldade de mensurar os custos da qualidade fez com que os registros contábeis fossem difíceis de obter com precisão. Em situações como essas, ainda podem ser classificados os custos da qualidade da seguinte forma: (i) custos-observáveis; e, (ii) custos-ocultos. Os custos da qualidade observáveis são aqueles disponíveis mediante os registros contábeis. Já os custos da qualidade ocultos são custos de oportunidade resultantes da má qualidade. Os custos-ocultos estão todos relacionados na categoria de falhas externas e podem ser divididos em 3 categorias: (i) vendas perdidas, relacionadas ao desempenho; (ii) insatisfação dos clientes; e, (iii) perdas de participação no mercado.

Alguns estudos e publicações fazem uma relação entre os custos de controle da qualidade e os custos de falhas. Robles Jr (1994), Slack et al. (1997) destacam que, os custos de falhas devem decrescer com o aumento dos custos de controle. Em função disso, há um ponto que representa o nível mínimo do total dos custos de qualidade, isto é, o equilíbrio ótimo entre os custos de controle e os custos de falhas, (ver Figura 4). Slack et al. (1997) afirmam que essa visão de que existe um valor ótimo destinado ao esforço de qualidade é ultrapassada, visto que este modelo foi muito criticado pelos defensores da Total Quality Management - TQM. 


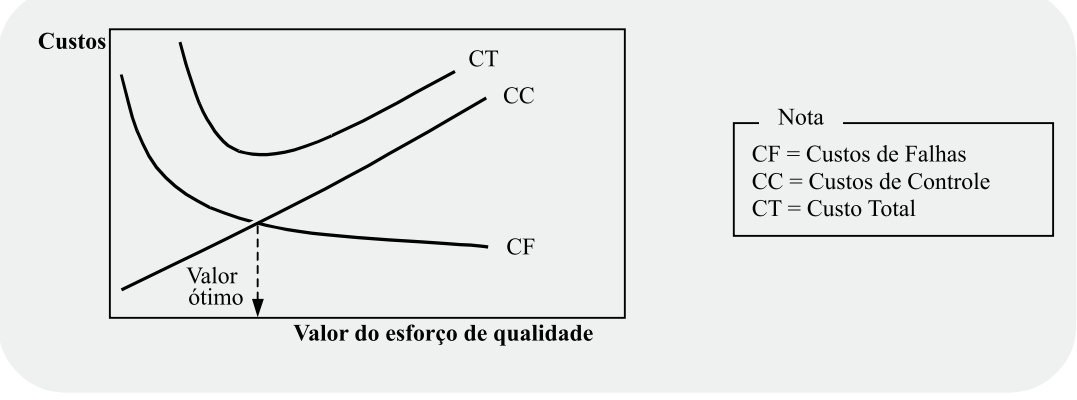

Figura 4: Modelo tradicional do custo da qualidade Fonte: Slack; Chambers; Harland; Harrison; Lohnston. (1997, p. 660).

Ainda, segundo Slack et al. (1997), o modelo tradicional do custo da qualidade implica que a falha e a má qualidade são aceitáveis e reconhece que o ponto "ótimo" é onde haverá erros. Além disso, assume que os custos são conhecidos e mensuráveis, entretanto, é reconhecido que há dificuldades de separar os custos da qualidade daqueles que são parte integrante da operação de manufatura. O conceito de nível "ótimo" de qualidade é rejeitado porque a TQM procura reduzir, através da prevenção de erros, todos os custos conhecidos e desconhecidos de falhas. Os autores afirmam, ainda, que se houver um nível ótimo de qualidade, este estará à direita, no sentido de empregar mais esforço na dução de custos, é a cooperação empresarial. Segundo Lipnack e Stamps (1982), as combinações inteligentes de pequenas empresas passam a representar vantagens competitivas, quando problemas e dificuldades que fazem parte do cotidiano dessas companhias são resolvidos em conjunto. As alianças podem atender a propósitos específicos, como: (i) comprar cooperativamente; (ii) comercialização conjunta; (iii) combinar recursos de pesquisa e desenvolvimento; (iv) treinamento cooperado; e, (v) estabelecimento de programas de qualidade.

Amato Neto (2000) acrescenta alguns benefícios da implementação da cooperação, tais como: (i) combinar competências e know-how; (ii) dividir gastos e compartilhar os benefícios de pesquisas tecnológicas; (iii) compartilhar riscos e custos de explorar novas oportunidades; (iv) oferecer uma linha de produtos diversificados e de qualidade superior; (v) exercer uma pressão maior no mercado com aumento de competitividade em benefício do cliente; (vi) compartilhar recursos; (vii) fortalecer o poder de compra; e, (viii) obter força para atuar no mercado internacional.

Esse fato é evidenciado na pesquisa realizada por Lima et al. (2004), onde foi comprovado economicamente que a parceria, ou como os autores denominaram "cooperação ambiental", pode resultar numa redução dos gastos relacionados com os materiais recicláveis em indústrias metalúrgicas. Este estudo demonstrou que a parceria na captação dos resíduos recicláveis (aço) poderia beneficiar os cooperados na venda dos mesmos para a siderúrgica, pois seria mais fácil atingir um "Lote Econômico de Venda" de sucatas, resultando num maior retorno financeiro e, conseqüentemente, na redução do impacto ambiental.

Klassen e McLaughlin (1996) afir-

As empresas precisam criar formas inteligentes de redução dos custos da qualidade. Existem métodos que já foram testados e pesquisados por várias organizações e estudiosos do assunto. Hansen e Mowen (2003) indicam uma estratégia de redução de custos que deve obedecer à seguinte ordem de priorização: (i) atacar os custos de falhas na tentativa de reduzí-los para zero; (ii) investir em melhorias através das atividades de prevenção; (iii) reduzir os custos de avaliação de acordo com os resultados obtidos; e, (iv) avaliar continuamente os esforços de prevenção com foco nas melhorias adicionais.

Outra estratégia que está muito difundida e que pode beneficiar as empresas em vários aspectos, inclusive na re- mam que, sob o ponto de vista estratégico, a organização deve considerar os impactos ambientais dos produtos e processos de manufatura, bem como a regulamentação ambiental na hora de formular sua estratégia corporativa. Existem mudanças nos componentes estruturais e de infra-estrutura, envolvendo escolha de produtos, tecnologias de processos e sistemas de gestão, que podem afetar a gestão ambiental. Através dessas mudanças nos componentes estruturais e de infra-estrutura, o desempenho financeiro pode ser afetado pela redução de custos ou por ganhos de mercado.

A definição de como os custos ambientais são atribuídos aos objetos de custos é de suma importância. Hansen e Mowen (2003) classificam os custos ambientais da seguinte 
forma: (i) custos de processo, onde os resíduos que degradam o ambiente são introduzidos neste meio, e, (ii) custos de pós-compra, onde o uso do produto ou seu descarte pode produzir degradação ambiental. A classificação dos custos ambientais é valiosa para a gerência, pois auxilia na tomada de decisões estratégicas. Para obter as informações referentes a custos é preciso utilizar o custeio baseado na função, onde se separam os custos ambientais dos custos indiretos de fabricação ou o custeio baseado em atividade, onde os custos são rastreados às atividades e destas aos produtos que os consomem.

A avaliação do custo de vida do produto, de acordo com Hansen e Mowen (2003), tem por objetivo descrever o modelo de avaliação através da gestão do produto e seus custos ambientais através de cinco estágios: (i) extração dos recursos, (ii) manufatura do produto, (iii) embalagem, (iv) uso do produto, e, (v) reciclagem ou descarte do produto. No entanto, é preciso avaliar esse processo obedecendo algumas etapas como, análise de estoque, no qual são especificados os tipos e quantidades das entradas de materiais e energia necessários e as liberações ambientais resultantes; análise de impacto, onde é avaliado o significado dos valores gerados pela etapa de análise de estoque e, também, os efeitos ambientais de projetos competidores, fornecendo uma classificação relativa de tais efeitos; e, análise de melhoria, onde é avaliado o impacto ambiental em termos operacionais e financeiros.

No estudo de Ceretta et al. (2003), ficou evidenciado que é possível obter benefícios econômicos e ambientais sem investimento ou com valores insignificantes com apenas uma reorganização do processo operacional ou mudança no layout. Muitos empresários acreditam que a implantação de uma gestão ambiental é onerosa e sem retorno significativo, mas com este estudo, foram constatadas várias medidas ambientais, implementadas com criatividade e inovação, que trouxeram grandes reduções nos orçamentos empresariais, comprovando que este paradigma deve ser revisto.

Outra pesquisa, realizada com empresas de reciclagem, fiscalizadoras e de aterros industriais, revelou uma preocupação com a redução de resíduos por parte das empresas geradoras, principalmente com o objetivo de minimizar o custo, e com a identificação de quais os resíduos que podem ser recuperados ou quais os que podem ser reprocessados. As empresas passaram a investir em programas de coleta seletiva, e aquelas já engajadas trataram de aperfeiçoar os sistemas existentes. Foi revelado que tem aumentado a preocupação com a destinação adequada dos resíduos nas empresas de grande porte. Entretanto, nas empresas de pequeno e médio porte esse fato ainda não é uma prática comum, porque os custos para o tratamento de resíduos ainda são considerados altos. Os resíduos não passam por um processo de avaliação que poderia determinar o envio para uma recicladora, ensejando uma maior utilidade para os negócios, e com isso aumentando a vida útil dos aterros (ASSAD, 2004).
Mas apesar das dificuldades existentes nos programas voltados à gestão ambiental, é possível observar uma crescente atenção das empresas quanto a esse tema. Em 2002 foi realizada uma pesquisa com empresas da região do Vale do Rio Pardo (RS) sobre os tipos de ações de responsabilidade e comprometimento com o meio ambiente. Na época, o estudo verificou que as organizações estavam bastante engajadas, realizando diversas ações a favor da preservação do meio ambiente. Os programas ambientais mais utilizados eram os seguintes, em ordem decrescente: (i) proteção aos trabalhadores (81,6\%); (ii) coleta seletiva de lixo $(65,3 \%)$; (iii) tratamento de resíduos, cursos/treinamentos, programa de economia de energia $(53,1 \%)$; (iv) tratamento de efluentes (47,0\%); (v) reciclagem de embalagens (41,0\%). A pesquisa evidenciou uma mudança no perfil das empresas, saindo de uma linha reativa (apenas cumprir a legislação) e partindo para uma linha mais pró-ativa na solução dos problemas ambientais (61,2\% das empresas entrevistadas). Este resultado demonstra a seriedade com que as organizações estão trabalhando com as questões relacionadas com o meio ambiente (BACKES, LEMOS e EICK, 2004).

Em outro estudo, Pires (2002) demonstrou a importância da Educação Ambiental no processo de conscientização dos atores envolvidos no processo de reciclagem numa indústria de produtos automotivos. A pesquisa demonstrou que a Educação Ambiental, por meio de treinamentos, palestras de sensibilização e cursos relacionados às questões ambientais fizeram com que a empresa conseguisse melhorar os resultados dos indicadores que representam as quantidades de resíduos que eram destinados à reciclagem e na diminuição dos resíduos que eram destinados ao aterro municipal, ou seja, houve um tratamento mais responsável dos resíduos gerados pela empresa, assumindo o comprometimento quanto à reciclagem e não simplesmente repassando a responsabilidade para o âmbito municipal.

Por fim, vale lembrar que a importância do reaproveitamento dos metais pode ser relacionada, pura e simplesmente, a três motivos básicos: (i) economia financeira - a reciclagem é mais barata que a extração do metal a partir do minério; (ii) economia de tempo - a reciclagem do metal é mais simples que a extração a partir do minério; e, (iii) conservação do ambiente - fazendo a reciclagem não há necessidade de tirar o minério da natureza. (BIBLIOTECA VIRTUAL DO ESTUDANTE BRASILEIRO, 2005).

\section{ASPECTOS METODOLÓGICOS}

Esta pesquisa é de caráter qualitativo, e foi fundamentada por meio de uma investigação do tipo exploratória na forma de um estudo de caso (Empresa X). De acordo com Cervo e Bervian (2002), a pesquisa exploratória auxilia na formulação de hipóteses significativas para posteriores pesquisas e tem como objetivo familiarizar-se com o fenômeno e descobrir novas 
idéias. Segundo Gil (2002), o método exploratório de pesquisa é utilizado para investigar e proporcionar uma visão geral, de tipo aproximativo, acerca do problema proposto.

Foi escolhido o estudo de caso por ser uma estratégia de pesquisa que contribui para a compreensão dos fenômenos individuais, organizacionais, sociais e políticos. Além do mais, o estudo de caso é uma pesquisa empírica que investiga um fenômeno contemporâneo dentro do seu contexto real, especialmente quando os limites entre fenômeno e o contexto não estão bem definidos e o pesquisador tem pouco ou nenhum controle sobre eles. Portanto, o objetivo do estudo de caso é expandir e generalizar teorias - generalização analítica. (YIN, 2001).

Este estudo foi realizado através da utilização de dados primários coletados junto à Empresa X, como também dados secundários extraídos da internet, documentos públicos, e pesquisa bibliográfica. Os dados primários foram obtidos através dos seguintes instrumentos de pesquisa: (i) entrevistas semi-estruturadas (questionários); e, (ii) observação in loco. Os dados secundários se referem à pesquisa realizada junto ao Sebrae para classificar a empresa estudada conforme os critérios de tamanho e porte. A utilização de múltiplas fontes de evidência, segundo Yin (2001), constitui o principal recurso de que se vale o estudo de caso para conferir significância a seus resultados. Os dados coletados correspondem ao período de 2005.

No tratamento dos dados foram utilizadas as seguintes técnicas: (i) seleção (exame minucioso e crítico dos dados); (ii) codificação (classificação); e, (iii) tabulação através de planilhas eletrônicas de cálculos (construção de tabelas, gráficos, fluxogramas e figuras). Para a análise dos dados foram utilizadas técnicas de interpretação e explicação. Dessa forma, pretende-se partir de dados puros para construção de informações, e sempre que possível realizar a ligação com a teoria.

A empresa investigada é uma pequena indústria metalúrgica localizada numa cidade circunvizinha à cidade de Curitiba. É uma organização familiar que produz estruturas metálicas, caçambas, e equipamentos para agroindústria, como silos e produtos para criação animal. Possui, também, alguma atividade na área da construção civil, como estruturas metálicas e mezaninos, bem como na prestação de serviços como instalação, manutenção industrial e projetos especiais (produtos personalizados - caldeiraria).

Quanto aos critérios de tamanho de empresas, para este estudo foram utilizados os parâmetros do Serviço Brasileiro de Apoio às Micro e Pequenas Empresas - Sebrae, que são baseados em duas entidades: (i) Governo Federal - de acordo com a receita bruta anual; e, (ii) Instituto Brasileiro de Geografia e Estatística (IBGE) - conforme o número de pessoal ocupado. Um dos critérios do Sebrae (Governo Federal) foi baseado no estatuto da Microempresa e da Empresa de Pequeno Porte, pela Lei no 9.841/99. Conforme este critério, são consideradas microempresas aquelas que possuem receita bruta anual igual ou inferior a $\mathrm{R} \$ 433.755,14$ e, pequenas empresas as que possuem receita bruta anual superior a $\mathrm{R} \$ 433.755,14$ e igual ou inferior a $\mathrm{R} \$ 2.133 .222,00$. Já os critérios do Sebrae baseados nos estudos do IBGE classificam as empresas da seguinte forma: (i) microempresa: na indústria até 19 pessoas ocupadas e, no comércio e serviços até 9 pessoas ocupadas; (ii) pequena empresa: na indústria de 20 a 99 pessoas ocupadas e, no comércio e serviços de 10 a 49 pessoas ocupadas.

\section{ESTUDO DE CASO}

A empresa em estudo utiliza recursos de otimização de processos e operações através de projetos de cortes onde se obtém a minimização de geração de resíduos com objetivo de maximizar o aproveitamento das peças. Esta é uma abordagem preventiva orientada para reduzir o volume e o impacto causado pelos resíduos. Esses projetos são realizados em CAD (projeto assistido por computador), no qual se procura desenvolver planos de corte e de manufatura obedecendo à filosofia prevencionista, tanto de custos como de impacto ambiental.

Porém, nenhum processo produtivo alcança o rendimento máximo teórico de $100 \%$, o que ainda implica em geração de resíduos e sobras, mesmo que em quantidades minimizadas. O destino desse volume de resíduos é a venda aos depósitos de reciclagem que fazem uma triagem de acordo com o tipo de metal para, posteriormente, na teoria, encaminhar para reaproveitamento nas siderúrgicas, através de fundição onde se obtém uma nova peça. Já as sobras são encaminhadas para o estoque para serem aproveitadas em outras ocasiões, uma vez que são peças novas porém com tamanhos diversos.

Todos os refugos da indústria metalúrgica, restos de perfis e chapas metálicas, são descartados para os depósitos de reciclagem. Além disso, existem outros materiais de aço que sobram do processo produtivo como, por exemplo, embalagens de tintas e solventes, pinos de rebites, tocos de eletrodo e arames de solda, restos de disco de desbaste, fitas de aço para embalagem e outros materiais diversos. No depósito de reciclagem se faz a separação, principalmente do ferro, que é separado dos outros metais como o alumínio, o cobre, o latão, etc. Esse é um dos fatores que influenciam no valor de venda da sucata, pois uma vez que os resíduos são classificados na própria fonte geradora, teriam um preço mais atrativo no mercado já que eliminar-se-ia a etapa de triagem nos depósitos de reciclagem.

A empresa adotou uma solução corretiva orientada para trazer de volta ao ciclo produtivo matérias-primas extraídas dos resíduos e sobras, através do reaproveitamento dos materiais, que antes eram descartados pela própria empresa, inserindo uma nova categoria de produtos: os produtos provindos de materiais reaproveitados, ou seja, as caçambas e containeres para armazenamento de materiais recicláveis. 
Contabilmente, esses materiais (resíduos) eram rejeitados e considerados custos da qualidade e custos ambientais, sendo classificados como passivos. A empresa perdia dinheiro na venda desses materiais por causa da desvalorização sofrida pela matéria-prima, cujo preço de venda ficava bem abaixo do valor pago ao fornecedor pelo mesmo montante de aço, conforme demonstrado na Figura 6. Comprava-se matéria-prima dos fornecedores e, em geral, $5 \%$ se perdia como sucatas ou como sobras de produção (tamanhos irregulares) que não poderiam ser aproveitados no processo produtivo. seu desenvolvimento e fabricação (valor agregado). Esse fato é devido à desvalorização do material, conforme a demonstração gráfica da Figura 7.

Além disso, anteriormente à iniciativa, os refugos de materiais ou resíduos da produção eram alocados de forma desorganizada dentro da organização. Esses materiais eram acumulados nos postos de trabalho e ficavam no local até atingir um volume que atrapalhasse o andamento normal do trabalho. Diante desse fato, esses materiais eram transferidos para outras localidades da empresa, muitas vezes para lugares diferentes, formando vários "focos" com resíduos. Em muitos casos, por falta de espaço físico, esses materiais eram colocados no exterior dos pavilhões da empresa, em contato direto com o ambiente externo. Somente quando não havia onde alocar esses resíduos ou quando os mesmos estavam atrapalhando o processo é que tomavam-se medidas de transferência para a empresa de reciclagem.

Esses resíduos não
Após a iniciativa de fabricação de caçambas e containeres através da utilização de resíduos e sobras de materiais provenientes do processo produtivo, a empresa passou a contabilizar essa ação (o produto) como ativo imobilizado, agregando valor para a organização e, conseqüentemente, para o resultado final da empresa. O que antes era contabilizado como custo da qualidade, ou seja, como perda do valor monetário da matéria-prima, agora é um bem agregado ao patrimônio da empresa, como qualquer outra máquina da fábrica. Vale lembrar que esse bem possui valor de mercado muito superior ao valor correspondente aos resíduos destinados ao

\begin{tabular}{|c|c|}
\hline \multicolumn{2}{|c|}{ Balanço Patrimonial } \\
\hline Ativo & \begin{tabular}{c} 
Passivo \\
\hline $\begin{array}{c}\text { Perda: } \\
\text { Custo da } \\
\text { qualidade } \\
\text { Ativo } \\
\text { Imobilizado }\end{array}$ \\
\hline
\end{tabular} \\
\hline
\end{tabular}

Figura 7: Do custo da qualidade ao ativo imobilizado

Fonte: Elaborado pelos autores. eram enviados antes porque, economicamente, os custos de transporte são maiores que o retorno da venda, devido ao lote reduzido deste material influenciar no LEC - Lote Econômico de Compra da empresa que adquire esses resíduos (depósitos de reciclagem) ou por não cobrir os custos de transporte da metalúrgica. Este fato é observado por Lima et al. em 2004, que perceberam que o LEC é uma das dificuldades que impediam uma adequada gestão dos resíduos ambientais, e sugeriram, então, a parceria (cooperação ambiental) como estratégia para reduzir os gastos com transportes e, conseqüentemente, favorecer uma gestão responsável quanto aos materiais recicláveis em indústrias metalúrgicas, resultando num maior retorno financeiro e, conseqüentemente, na redução do impacto ambiental.

Após a fabricação de uma caçamba, a partir de retalhos e sobras de chapas e perfis de aço, a empresa organizou melhor seu parque produtivo, tanto no aspecto visual como no fluxo de pessoas e materiais. Atualmente, os resíduos não são acumulados nas áreas de trabalho como anteriormente. Essas áreas são mais organizadas e limpas já que o colaborador responsável pelo setor não deixa acumular resíduos de forma desorganizada.

Os processos de confecção de um produto reciclado demandam uma quantidade maior de 
tempo, uma vez que se assemelham aos produtos artesanais. Apesar disso, mesmo com a baixa produtividade, é viável produzir as caçambas e contêineres devido à utilização de matérias-primas recicladas que antes eram vendidas a preços irrisórios, sem contar com o ativo que a empresa agrega e os aspectos relacionados à organização dos materiais e imagem interna e externa. Ao invés de utilizar uma peça (chapa e perfil de aço) inteira, a caçamba foi montada com restos de materiais de mesma espessura e padrão dos materiais novos, conforme a Figura 8. é possível estimar os benefícios financeiros deste projeto, ou seja, só de materiais são alocados ao produto $0,22 \times 180$ $=\mathrm{R} \$ 39,60$.

Na Tabela 1 pode ser observada uma projeção dos custos envolvendo duas alternativas: (i) caçamba convencional - fabricada a partir da compra de matéria-prima nos padrões de tamanho da usina siderúrgica; e, (ii) caçamba "ecológica" - fabricada com retalhos de materiais e sobras da produção. É possível notar que a diferença dos custos é bastante relevante ( $\mathrm{R} \$ 502,98$ - $\mathrm{R} \$ 218,37)$, resultando num benefício ou ganho de $\mathrm{R} \$ 284,61$. Não foi considerada a depreciação no cálculo, pois acredita-se que o valor é praticamente igual para ambos os casos, não afetando de forma significativa o resultado final (diferença entre as alternativas).

Além disso, os ganhos econômicos não são estáticos. Quando se constrói uma caçamba a partir de sobras de produção, os benefícios que podem ser mensurados não são somente na reutilização dos materiais que foram alocados

Figura 8: Elaboração do mosaico de chapas recicladas Fonte: Elaborado pelos autores.

Por meio da observação da Figura 8, é possível perceber que são realizados encaixes das chapas. Além disso, são feitos recortes de retalhos de chapas para que se obtenham os encaixes quando necessários, de forma a montar as peças retangulares nas dimensões exigidas pelo projeto. O processo é semi-artesanal, análogo a um mosaico. Inicialmente, são montadas as chapas retangulares ou no tamanho maior ao projeto, para depois cortar conforme as especificações. Uma equipe foi dividida entre montadores e soldadores. O objetivo dos montadores é montar a caçamba através da união dos retalhos de chapas, medindo e ponteando (pontos de solda) toda a caçamba. Somente após a caçamba estar erguida é que os soldadores executam a tarefa de soldar cordões uniformes e conforme o projeto. De forma similar, alinham-se perfis metálicos tipo viga "U", cantoneiras e tubos quadrados e retangulares, de forma a obter barras nos tamanhos especificados pelo projeto.

Uma caçamba produzida a partir de resíduos industriais novos não pode ser considerada velha, pois são utilizados na fabricação restos de chapas novas, de tamanhos diversos e irregulares. Além disso, os técnicos da empresa garantem a resistência da caçamba fabricada com retalhos. A caçamba "Nova" ou "Normal", fabricada com a mesma bitola de chapa, mas utilizando matéria-prima "inteira" (chapas e perfis sem emendas), possui um valor aproximado de $\mathrm{R} \$ 1.750,00$. Considerando que a empresa recebe $R \$ 0,22$ centavos por quilo $(\mathrm{kg})$ de aço reciclável, e que uma caçamba pesa, aproximadamente, $180 \mathrm{~kg}$, à sua produção. As vantagens são contínuas, pois a empresa conseguiu obter uma quantidade de material reciclável (Lote Econômico de Resíduos Metálicos) maior e de maneira mais organizada, que pôde ser vendido por preços mais atrativos e com maior retorno para a organização, bem como uma maior organização nas instalações e, quem sabe, uma melhora na imagem perante o público interno e externo.

\begin{tabular}{l|r|r}
\hline \multicolumn{3}{c}{ Comparação de custos das alternativas } \\
\hline \multicolumn{1}{c|}{ Descrição } & $\begin{array}{c}\text { Caçamba } \\
\text { convencional (R\$) }\end{array}$ & $\begin{array}{c}\text { Caçamba } \\
\text { "ecológica" (R\$) }\end{array}$ \\
\hline Mão-de-obra - montador/acabamento & 18,04 & 42,48 \\
\hline Mão-de-obra - soldador & 30,22 & 75,04 \\
\hline Matéria-prima & 396,00 & 39,60 \\
\hline Resíduos (projeção 5\% de perda) & 19,80 & 1,98 \\
\hline Venda do resíduo para reciclagem & $-4,36$ & $-0,44$ \\
\hline Acabamento (lixa, desbaste, pintura, etc) & 25,00 & 32,00 \\
\hline Outros materiais (eletrodo, disco de corte, etc) & 9,80 & 15,80 \\
\hline Equipamento de proteção individual - EPI’s & 0,46 & 0,46 \\
\hline Energia-elétrica & 8,02 & 11,45 \\
\hline Total & $\mathbf{5 0 2 , 9 8}$ & $\mathbf{2 1 8 , 3 7}$ \\
\hline
\end{tabular}

Fonte: Dados fornecidos pelo departamento de produção da empresa pesquisada.

É óbvio que esta ação da empresa não representa uma inovação radical, mas certamente possui um caráter inovador na medida em que reutiliza as sobras metálicas da produção para apoiar a própria produção. Essa inovação pode ser classificada como uma inovação mista, uma vez que houve uma nova concepção de produto (caçamba construída a partir de retalhos), e um aprimoramento do processo de produção em virtude dos benefícios que esse produto proporcionou para o processo. Portanto, pode-se afirmar que esta ação acarretou numa inovação de produto e processo. 
Diante dos benefícios alcançados de imediato, a organização estuda a possibilidade de confeccionar mais caçambas e contêineres para utilizá-los de maneira mais responsável em termos econômicos e ambientais. Pretende-se treinar os colaboradores para trazer classificados os materiais, em seus respectivos compartimentos, e da seguinte forma: (i) aço; (ii) alumínio; (iii) plástico; (iv) papel; e, (v) madeira. Esses materiais estão presentes no dia-a-dia da empresa e podem reduzir os custos e despesas relacionadas com o manejo e remanejo dos materiais, bem como fomentar a classificação na fonte gera- dora. Este fato corrobora com a tese de Ritzman e Krajewski (2003), que afirmam que os custos de retrabalho se referem aos gastos relacionados quando um item é encaminhado novamente a alguma operação prévia, no caso da empresa pesquisada, custos com mudanças dos materiais para diferentes locais de armazenagem.

No período anteriormente a essa inovação, os resíduos encontravam-se espalhados em pequenos focos pela empresa. Não existia um controle visual do problema, visto que a maneira de como a empresa "organizava" as sobras e sucatas

\begin{tabular}{|c|c|c|}
\hline Variável analisada & Antes da solução & Depois da solução \\
\hline Lay out & $\begin{array}{l}\text { Os pontos de geração de resíduos eram } \\
\text { distantes entre si. Não havia planejamento da } \\
\text { logística interna dos materiais recicláveis. }\end{array}$ & $\begin{array}{l}\text { Preocupação maior com o planejamento do } \\
\text { lay out em função da logística interna dos } \\
\text { resíduos. Aproximação de alguns pontos de } \\
\text { geração de resíduos de modo a facilitar a } \\
\text { coleta. }\end{array}$ \\
\hline Limpeza & $\begin{array}{l}\text { Muitos focos com resíduos. Em diversos } \\
\text { pontos da fábrica era possível encontrar } \\
\text { acúmulo de resíduos. }\end{array}$ & $\begin{array}{l}\text { Os resíduos são depositados somente em um } \\
\text { único local - na caçamba. }\end{array}$ \\
\hline Conservação dos resíduos & $\begin{array}{l}\text { A conservação dos resíduos não era adequada, } \\
\text { inclusive havendo perda do peso do material } \\
\text { por meio de deterioração (ferrugem). }\end{array}$ & $\begin{array}{l}\text { Resíduos mais conservados. } \\
\text { A caçamba é mais adequada à conservação } \\
\text { dos resíduos metálicos. }\end{array}$ \\
\hline Funcionários & $\begin{array}{l}\text { Indiferentes ou desmotivados devido à } \\
\text { aparência da fábrica não ser adequada a um } \\
\text { bom ambiente de trabalho. Não havia muita } \\
\text { colaboração e participação nas questões } \\
\text { envolvendo a gestão dos resíduos. }\end{array}$ & $\begin{array}{l}\text { Motivados, inclusive opinando com críticas e } \\
\text { sugestões para o ambiente e para melhorias na } \\
\text { coleta dos resíduos. }\end{array}$ \\
\hline Público externo/ clientes & $\begin{array}{l}\text { A empresa não tinha interesse em mostrar as } \\
\text { instalações da fábrica. }\end{array}$ & $\begin{array}{l}\text { As instalações da empresa são mostradas } \\
\text { como um "diferencial" para os clientes. A } \\
\text { fábrica ficou mais organizada e limpa. }\end{array}$ \\
\hline Custo Ambiental & $\begin{array}{l}\text { Ocorria muito retrabalho devido à } \\
\text { reorganização, triagem e armazenamento dos } \\
\text { resíduos para reciclagem, ocasionando } \\
\text { aumento nos custos ambientais. Não existia } \\
\text { um controle adequado dos custos. }\end{array}$ & $\begin{array}{l}\text { A organização dos resíduos proporcionou uma } \\
\text { redução dos custos, não existe o retrabalho de } \\
\text { coleta, triagem e armazenamento. Quando o } \\
\text { resíduo é gerado, é colocado no local } \\
\text { adequado. }\end{array}$ \\
\hline Investimentos & Não existiam. & $\begin{array}{l}\text { A empresa começou a rever sua política } \\
\text { ambiental. A caçamba agregou valor ao } \\
\text { patrimônio da empresa. }\end{array}$ \\
\hline Preço de venda dos resíduos & $\begin{array}{l}\text { Os preços não eram atrativos, porque a falta } \\
\text { de uma triagem adequada inviabiliza a venda } \\
\text { dos resíduos por preços melhores. }\end{array}$ & $\begin{array}{l}\text { Preços mais atrativos, já que os depósitos de } \\
\text { reciclagem pagam mais pelo resíduo } \\
\text { classificado. }\end{array}$ \\
\hline Fluxo do processo & $\begin{array}{l}\text { Desorganizado e com muitos pontos de } \\
\text { retroação, paradas e retrabalho, pois em } \\
\text { determinadas ocasiões era preciso focar as } \\
\text { atenções para os resíduos devido ao acúmulo } \\
\text { desordenado. }\end{array}$ & $\begin{array}{l}\text { Mais organizado, mais contínuo. Redução dos } \\
\text { pontos de retrabalhos e eliminação dos pontos } \\
\text { de sobrestamento na produção destinada } \\
\text { exclusivamente para remoção dos resíduos. }\end{array}$ \\
\hline $\begin{array}{l}N^{o} \text { de pontos de geração de } \\
\text { resíduos }\end{array}$ & \multicolumn{2}{|c|}{$\begin{array}{l}\text { Não houve mudança na quantidade de pontos de geração de resíduos, pois a solução adotada foi } \\
\text { na organização da armazenagem dos mesmos. A empresa somente aproximou alguns pontos de } \\
\text { geração de modo a facilitar a coleta. }\end{array}$} \\
\hline Gestão dos resíduos & $\begin{array}{l}\text { Característica reativa. Não existia uma } \\
\text { preocupação adequada quanto à gestão dos } \\
\text { resíduos. Os colaboradores não eram } \\
\text { convidados a participar do processo de gestão } \\
\text { dos resíduos. }\end{array}$ & $\begin{array}{l}\text { Característica pró-ativa. Existe uma } \\
\text { preocupação maior com os resíduos. O } \\
\text { planejamento e a gestão dos resíduos fazem } \\
\text { parte do cotidiano da empresa. Envolvimento } \\
\text { dos colaboradores no processo de gestão dos } \\
\text { resíduos. }\end{array}$ \\
\hline
\end{tabular}

Quadro 1: Comparação entre a alternativa adotada e a antiga situação

Fonte: Elaborado pelos autores. 
não favorecia esse controle. No Quadro 1 encontra-se um estudo onde foi priorizada a análise de algumas variáveis no sentido de comparar os fatos e resultados entre antes e depois da implantação das melhorias ou solução adotada para armazenar os resíduos.

Em muitas ocasiões, a empresa por não ter um local adequado à armazenagem, colocava os resíduos metálicos no relento, exposto ao sol e a chuva, enferrujando e se desmanchando pelo chão, atingindo, muitas vezes, o solo. Os produtos de ferro e aço utilizados na produção como, por exemplo, as chapas de aço, quando expostos a um ambiente inadequado para armazenagem (com muita umidade), afinam devido ao desprendimento de camadas de aço enferrujado, ocasionando uma perda de peso e, conseqüentemente, prejuízo para a empresa no ato da venda desses resíduos para os depósitos de reciclagem.

O meio ambiente é favorecido, também, quando as sucatas de ferro e aço são recicladas, pois na teoria, a indústria siderúrgica diminui a exploração de jazidas e minas para obter a matéria-prima para fabricação do aço. Essa exploração degrada a fauna, a flora, o solo e lençóis freáticos, porque é preciso remover florestas para a construção de minas de ferro e estradas para o transporte. Altera-se a paisagem e inutiliza-se o terreno. Conforme a abordagem publicada no documento disponível na Biblioteca Virtual do Estudante Brasileiro (2005), a reciclagem de ferro e aço traz benefícios como: (i) economia financeira - a reciclagem é mais barata que a extração do metal a partir do minério; (ii) economia de tempo - a reciclagem do metal é mais simples que a extração a partir do minério; e, (iii) conservação do ambiente - fazendo a reciclagem não há necessidade de tirar o minério da natureza.

\section{CONCLUSÕES}

No minério, o metal geralmente está ligado ao oxigênio. Portanto, quando se transporta o minério da mina até a fábrica, onde se separa o oxigênio do metal, a empresa está gerando gastos com o transporte de oxigênio. Na sucata, o metal está sem oxigênio. Por outro lado, ele pode estar coberto de tinta, plástico e outros materiais, mas isso não é relevante. Reciclar metais é importante porque assim eles não se acumulam como lixo. Porém, em ambas as situações, existem emissões de partículas na atmosfera tais como: partículas totais em suspensão (PTS), partículas inaláveis (PI), hidróxidos de nitrogênio (NOx), hidróxidos de enxofre (SOx), ozônio (O3), benzeno, tolueno, xileno, metano e hidrocarbonetos não-metanos (HCNM).

A solução convencional de reciclagem do metal através de fundição é interessante até o momento em que não existam possibilidades de utilização do metal. A empresa objeto deste estudo soube inovar a partir de um problema: adotou uma solução para os resíduos metálicos sem, necessariamente, acarretar gastos dispendiosos para a organização. Pelo contrário, no final das contas a empresa conseguiu acrescentar um bem ao seu patrimônio, valorizar os resíduos metálicos utilizados na fabricação das caçambas, preservar o meio ambiente, além de conseguir armazenar e classificar uma quantidade de resíduos considerável, que permitisse um valor maior na venda.

Houve, também, um benefício intangível, ou de difícil mensuração, relacionado com a organização das dependências e estrutura fabril, melhorias no lay out, motivação dos funcionários e melhoria na imagem e estética da empresa. Caso a empresa consiga levar adiante o projeto de confecção de caçambas e contêineres para a coleta de outros materiais que são utilizados direta ou indiretamente nas suas operações, certamente poderá trazer mais benefícios em termos operacionais e ambientais e, se possível, econômicos.

Quanto às desvantagens, existe uma que está relacionada com a logística envolvida neste processo. Muitos depósitos não possuem caminhão do tipo Bruck, especial para transportar caçambas. Além disso, certos Brucks precisam de adaptação nas correntes que levantam a caçamba, ou seja, não existe uma padronização deste sistema de coleta. Existe uma diferença entre os fabricantes de Brucks quanto à distância entre os pinos que sustentam a caçamba e à relação gancho-basculante. Portanto, a empresa possui uma restrição na venda de sucatas, tendo que vendê-las para os depósitos de resíduos que atendam a essa necessidade.

Outra desvantagem, se é que pode ser considerada, está relacionada com o trabalho despendido para fabricar as caçambas e contêineres do tipo "mosaico". Realmente, este processo de selecionar, juntar, soldar, medir, cortar, juntar, montar, soldar, medir, cortar,...e assim por diante, é muito trabalhoso. Porém, de um outro ponto de vista, este processo está dando emprego para as pessoas envolvidas, valorizando resíduos e preservando o meio ambiente.

Como sugestão, fica registrado que a empresa poderia utilizar caçambas menores, instaladas diretamente nas fontes geradoras de resíduos, destinadas ao correto armazenamento e separação das sobras no momento das operações, eliminando assim o processo de triagem e ao mesmo tempo organizando e reduzindo o mau aspecto da organização. Posteriormente, essas caçambas menores, depois de cheias, podem ser transportadas para os contêineres maiores.

Além disso, é muito importante que a empresa promova uma política de redução de resíduos na fonte geradora. Isso poderia ser realizado por meio de exercícios de conscientização dos colaboradores, fornecedores e clientes, como também pela utilização de ferramentas da qualidade. É possível que medidas como essas pudessem proporcionar um resultado muito mais satisfatório para a empresa e para o meio ambiente.

Este estudo procurou explicitar para a comunidade técnica e científica uma solução alternativa de aplicação dos 
resíduos e sobras de produção de uma indústria metalúrgica. Convencionalmente, os resíduos metálicos são destinados para a reciclagem. A solução adotada pela empresa foi relacionar a construção da caçamba "ecológica" com o projeto de classificação dos resíduos, ou seja, as caçambas feitas de retalhos são utilizadas no apoio de um projeto de triagem, separação e coleta dos resíduos industriais. Além de preservar o meio-ambiente, o projeto aumentou o capital da empresa e reduziu as perdas com os resíduos.

Outra contribuição deste estudo diz respeito à importância que as organizações estão dando para os projetos que procuram otimizar os recursos naturais utilizados no processo de produção. São projetos que priorizam a eco-eficiência, tendo como objetivo a redução do impacto ambiental, resultando em benefícios para o meio ambiente e para a economia da empresa. São processos produtivos que integram os fatores econômicos e sociais sem agredir o meio ambiente. Este estudo é mais um caso que vem reforçar a importância da eco-eficiência nos negócios.

Este estudo de caso evidencia que atitudes simples e inovadoras podem trazer benefícios operacionais, ambientais e econômicos. É importante frisar a dificuldade que as pequenas empresas têm para sobreviver num mercado altamente competitivo e, mesmo assim, com todos os problemas e percalços do cotidiano empresarial brasileiro, surgem ações que comprovam a importância de se arriscar em projetos inovadores. Isto reforça o caráter empreendedor da classe empresarial brasileira, que muitas vezes inova com os recursos que possui e consegue sobreviver sem muito apoio, fomento e incentivo.

\section{REFERÊNCIAS}

AMATO NETO. J. Redes de cooperação produtiva e clusters regionais: oportunidades para as pequenas e médias empresas. São Paulo: Atlas e Fundação Vanzolini, 2000.

ANDRADE, R. O. B.; TACHIZAWA, T.; CARVALHO, A. B. Gestão Ambiental: enfoque estratégico aplicado ao desenvolvimento sustentável. 2. ed. São Paulo: Pearson Education - Makrons Books, 2002.

ASSAD, M. M. N. Responsabilidade Social Sob a Perspectiva de Sustentabilidade: o Médio Vale do Paraíba e os Resíduos Sólidos Industriais. In: XXVIII EnANPAD, Curitiba, 2004.

BACKES, B. I.; LEMOS, A. D. C.; EICK, C. L. O Comprometimento com o Meio Ambiente: Um Estudo nas Empresas da Região do Vale do Rio Pardo - RS. In: XXVIII EnANPAD, Curitiba, 2004.

BIBLIOTECA VIRTUAL DO ESTUDANTE BRASILEIRO. Para onde vão as sucatas de ferro. Disponível em: <www.bibvirt. futuro.usp.br/textos/exatas/quimica/tec2000/q20d.pdf>. Acesso em: 06 abr. 2005.

BRAGA, B.; HESPANHOL, I.; CONELO, J. G. L.; VERAS JR., M. S.; PORTO, M. F. A.; NUCCI, N. L. R.; JULIANO, N. M. A.;
EIGER, S. Introdução à engenharia ambiental. São Paulo: Prentice Hall, 2002.

BORN, R. H. Grandes desafios para a gestão ambiental. Boletim Fundação Vanzolini, São Paulo, ano 9, n. 42, p. 5, mar./abr. 2000.

CAMPOS, V. F. TQC: controle da qualidade total (no estilo japonês). 6. ed. Belo Horizonte, Fundação Christiano Ottoni, 1992.

CERETTA, P. S.; LIMA, S. R.; ROCHA, A. M. C.; SONZA, I. B. Responsabilidade social: gestão ambiental pode gerar lucro. In: III CONGRESSO USP CONTROLADORIA E CONTABILIDADE, São Paulo, 2003.

CERVO, A. L.; BERVIAN, P. A. Metodologia científica. 5. ed. São Paulo: Prentice Hall, 2002.

DAVIS, M. M.; AQUILANO, N. J.; CHASE, R. B. Fundamentos da administração da produção. 3. ed. Porto Alegre: Bookman, 2001.

FEIGENBAUM, A. V. Controle da qualidade total: gestão e sistemas. v. 1. São Paulo: Makron Books, 1994.

FIGUEIREDO, L. H. M. Sistema flexível e eficaz para o gerenciamento e a tomada de decisão baseados no risco. Gerenciamento Ambiental. São Paulo, ano3, n. 16, p. 47-49, set./out. 2001

GIL. A. C. Como elaborar projetos de pesquisa. 4. ed. São Paulo: Atlas, 2002.

HANSEN, D.; MOWEN, M. M. Cost Management. Ohio: Thonsson, 2003.

KLASSEN, R. D.; McLAUGHLIN, C. P. The impact of environmental management on firm performance. Management Science, v. 42, n. 8, p. 1199-1213, Aug. 1996.

LAGE, H. Passivo ambiental. Meio ambiente industrial. São Paulo, ano 7, n. 41, p. 32-34, jan./fev. 2003.

LIMA, S. R.; CERETTA, P. S.; ROCHA, A. M. C.; SONZA, I. B. Gerenciamento dos resíduos renováveis em indústrias metalúrgicas. In: XI CONGRESSO BRASILEIRO DE CUSTOS, Porto Seguro-BA, 2004.

LIPNACK, J.; STAMPS, J. The networking book. Routledge and Regan Paul: New York, 1982.

PIENIZ, L. P. A identificação dos custos ambientais - o caso do cortume Monbelli Ltda. - Tapera/RS. In: VIII CONGRESSO BRASILEIRO DE CUSTOS: a controladoria no novo contexto organizacional. Universidade do Vale do Rio dos Sinos, São Leopoldo, 2001.

PIRES, J. A. Reciclagem: Coleta seletiva na indústria - um estudo de caso. 2002. Trabalho de Conclusão de Curso. (Graduação em Ciências Econômicas) - Universidade do Vale do Paraíba. Disponível em: <http://www.univap.br/biblioteca/hp_dez_2002/tgs.htm>. Acesso em: mai. 2006.

RITZMAN, L. P.; KRAJEWSKI, L. J. Foundations of operations management. Prentice-Hall Publishers: Upper Saddle River: NJ, 2003.

ROBLES JR, A. Custos da qualidade: uma estratégia para a competição global. São Paulo: Atlas, 1994.

SEBRAE - SERVIÇO BRASILEIRO DE APOIO ÀS MICRO E PEQUENAS EMPRESAS. Disponível em: <www.sebrae.com.br>. Acesso em: 15 fev. 2005.

SLACK, N.; CHAMBERS, S.; HARLAND, C.; HARRISON, A.; JOHNSTON, R. Administração da produção. 1. ed. São Paulo: Atlas, 1997.

YIN, R. K. Estudo de Caso: planejamento e métodos. 2. ed. Porto Alegre: Bookman, 2001. 